\title{
TRÊS LEITORES
}

\section{Bruna Carolina Domingues dos Santos Carvalho UNIRIO - CAPES}

RESUMO: A novela Palmeiras selvagens, de William Faulkner, dispara, neste artigo, o gesto anacrônico e arquifilológico com o qual procede 0 crítico Raúl Antelo em boa parte de suas reflexões: o gesto de, em vez de ler um texto em si mesmo ou em seu autor, lê-lo em seu leitor. Persigo, em vestígios dispersos por entre cartas, diálogos, entrevistas, a montagem de uma cena em que os cineastas Glauber Rocha, Jean-Luc Godard e o escritor Jorge Luis Borges travam uma conversa silenciosa em torno desse um livro. Tais traduções e leituras frustram formalizações e desobedecem a cânones. Produzem-se aos saltos, tal como projetou Macedonio Fernández em seu Museo de la novela de la eterna.

PALAVRAS-CHAVE: Leitura; Tradução; Anacronismo.

\section{THREE READERS}

ABSTRACT: The novel Wild Palms, written by William Faulkner, triggers, on this article, an anachronic and archiphilological gesture, which appears in Raúl Antelo's essays: the gesture of reading a text on its reader, instead of reading it on itself, or on its author. I pursue, through trace elements left on letters, interviews and dialogues, in order to settle a scene in which the filmmakers Glauber Rocha and Jean-Luc Godard and the writer Jorge Luis Borges talk silently about this book. Those readings and translations frustrate any kind of formalization and do not obey canons. They make themselves by jumping, as projected by Macedonio Fernández on his Museo de la novela de la eterna.

KEYWORDS: Reading; Translation; Anachronism.

Bruna Carolina Domingues dos Santos Carvalho é mestranda em Memória Social no Programa de Pós-Graduação em Memória Social da Universidade Federal do Estado do Rio de Janeiro. 


\section{TRÊS LEITORES}

\section{Bruna Carolina Domingues dos Santos Carvalho}

Na cidade de Salvador, em 1963, Glauber Rocha senta-se diante de sua máquina de escrever e datilografa uma $\operatorname{carta}^{1}$ ao amigo e também cineasta Paulo César Saraceni. A correspondência, como tantas outras que redigiu, é uma montagem caótica de sentenças separadas entre si por cortes secos e com conteúdos díspares. Uma frase quase nunca antecipa o assunto daquela que está por vir. Inicia o texto com uma apaixonada discordância à "crítica de merda"2 que se faz no Brasil. Na mesma linha em que promete "quebrar os óculos"3 do crítico Ely Azeredo em uma porrada, confessa seu amor por Gerta, com quem diz viver um romance "total, sem briga, psicologia, ciúme, futuro, nada. imagine, é como só música barroca de Corelli, o amor pelo amor." ${ }^{4} \mathrm{Em}$ seguida, convoca Angústia, de Graciliano Ramos ("um folhetim brasileiro com o peso de Dostoiévski"5), e, além de imaginar a adaptação do livro em filme, estipula a Saraceni que o dirija.

Passa a estabelecer - no tom impositivo que adota com constância quem dentre os partícipes do Cinema Novo deveria executar o quê, de que maneira e em que momento, como se soubesse com clareza quais os passos deveriam ser cumpridos pelo movimento em prol de um cinema original em sua fome e em seu compromisso com a verdade, como ele mesmo delinearia dois anos depois em conhecido manifesto. ${ }^{6}$ Elogios ao amigo ("você era nosso

${ }^{1}$ ROCHA, Glauber. Cartas ao mundo. Ivana Bentes (Org.). São Paulo: Companhia das Letras, 1997, p. 191.

2 Ibidem, p. 191.

3 Ibidem, p. 191.

${ }^{4}$ Ibidem, p. 191.

5 Ibidem, p. 191.

${ }^{6}$ Redigido por Glauber para um Congresso em Gênova, Eztétyka da fome apresenta a existência de um evolucionismo interno ao Cinema Novo. Escreve Glauber: "Foi seu próprio miserabilismo, que, antes escrito pela literatura de 30, foi agora fotografado pelo cinema de 60; e, se antes era escrito como denúncia social, hoje passou a ser discutido como problema político. Os próprios estágios do miserabilismo em nosso cinema são internamente evolutivos. Assim, como observa Gustavo Dahl, vai desde o fenomenológico (Porta das Caixas), ao social (Vidas Secas), ao político (Deus e o Diabo), ao poético (Ganga Zumba), ao demagógico (Cinco vezes Favela), ao experimental (Sol Sobre a Lama), ao documental (Garrincha, Alegria do Povo), à comédia (Os Mendigos), experiências em vários sentidos, frustradas umas, realizadas outras, mas todas compondo, no final de três anos, um quadro histórico que, não por acaso, vai caracterizar o período Jânio-Jango". ROCHA, Glauber. Eztétyka da fome. In: Hambre: espacio cine experimental, set. 2013, p. 2. 
Modigliani"7), misturam-se a conselhos ("tem que trabalhar, estudar, criar"8) e emendam-se a uma entusiasmada referência à novela Palmeiras Selvagens, escrita em 1939 por William Faulkner. ${ }^{9}$ Detenho-me nela:

No fim do romance As palmeiras bravas, de Faulkner, que você faria o maior filme do mundo, o personagem diz: 'a memória não pode viver fora da carne. a memória sem carne é o nada. entre o nada e a dor eu fico com a dor' - e então não se suicida, para se lembrar, na dor, da mulher que morreu num aborto que ele mesmo tentou fazer. é uma tragédia total, genial. ${ }^{10}$

O personagem Harry Wilbourne, de Faulkner, é o autor da frase sublinhada por Glauber. Sua história é a de um ingênuo residente de medicina que se apaixona carnalmente por Charlotte Rittenmeyer, uma mulher casada. Juntos, eles vão viver uma paixão nômade, cujo cenário varia entre Illinois e Utah, e sobreviverão por meio de trabalhos temporários, braçais e latas de comida contadas. Como sugeriu Glauber a Saraceni, experimentar esse desejo até então inédito na vida de Harry provoca sua ruína: Charlotte engravida e o convence a realizar um aborto, que, mal sucedido, provoca sua morte. Ele, por sua vez, termina em uma cela em Louisiana, onde se mantém vivo somente para sofrer.

Os capítulos de Palmeiras selvagens são intercalados pelos de uma outra narrativa: $O$ Velho, a história de um condenado preso pela tentativa de assaltar um trem. Ele é liberto provisoriamente para salvar as vítimas de uma das maiores enchentes da história do rio Mississippi - o Old man do título. Sua luta pela sobrevivência, assim como a de Harry, está atada a uma mulher, mas não da mesma maneira. O condenado salva uma grávida por quem não nutre um declarado desejo, mas a quem se une no enfrentamento da fúria do rio.

Interessa-me menos, no espaço deste artigo, analisar a novela de William Faulkner como uma obra acabada, cristalizada, como um objeto a ser destrinchado, seja do ponto de vista crítico, literário ou histórico linear. Aqui, proponho lê-la através de alguns de seus leitores ${ }^{11}$, no intuito não de chegar a um lugar, a um destino conhecido de antemão, mas de mantê-la tensionada, potente. Perseguirei, em vestígios dispersos por entre cartas, diálogos e

\footnotetext{
7 Idem, Cartas ao mundo, op. cit., p. 193.

8 Ibidem, p. 193.

9 FAULKNER, William. Palmeiras selvagens. São Paulo: Cosac Naify, 2003.

${ }^{10}$ ROCHA, Glauber. Cartas ao mundo, op. cit., p.193.

${ }^{11}$ LIMA, Manoel Ricardo de. Arquifilologias: ficção crítica, memórias inaparentes. Notas de aula, Programa de Pós-Graduação em Memória Social, Universidade Federal do Estado do Rio de Janeiro, 2017.
} 
entrevistas, a montagem de uma cena de leitura, em que três leitores-autores travam uma conversa silenciosa a partir desse mesmo um livro.

Esse procedimento não guarda nenhuma novidade. Em Destruição e anacronismo, Raúl Antelo apresenta ${ }^{12}$ o crítico de arte Gustav Glück, pai de um banqueiro homônimo, amigo de Walter Benjamin nos anos 1930, a quem o filósofo alemão dedica seu ensaio sobre Karl Krauss. Antelo pontua que, no livro de Glück-pai acerca da arte da Renascença fora da Itália, o crítico toma a pintura do holandês Pieter Bruegel como caso exemplar da prática de uma montagem anacrônica: sua versão da bíblica Torre de Babel é arquitetada como se própria do século XVI; o Censo de Belém é ambientado em uma paisagem identificada à holandesa, e assim por diante:

Gustav Glück [...] defendera, em mais de uma ocasião, a questão do anacronismo como procedimento de renovação estética, questão essa que nos levaria, muito mais adiante, com Didi-Huberman, à consciência de que a história só pode ser anacrônica (através da montagem) e de que só podemos ambicionar uma história dos anacronismos (através do sintoma). ${ }^{13}$

Antelo lê os quadros de Bruegel através do leitor Glück, o qual atribui ao anacronismo a modernidade do artista holandês. E vai além: procura a contaminação desse anacronismo (esse mosaico de diferentes paisagens e tempos) em um outro leitor de Glück além dele próprio: Bertold Brecht. Esse gesto também anacrônico de Antelo aproxima-se daquele com o qual Roland Barthes caracteriza a própria leitura: como o gesto do infinito deslocamento, ciência do inesgotamento. ${ }^{14} \mathrm{Ou}$, em outras palavras, aproxima-se do método regressivo sugerido por alguém na biblioteca de Babel de Jorge Luis Borges: para chegarmos ao livro $A$, consultamos previamente um livro $B$ que indique $o$ lugar de $A$; para localizarmos o livro $B$, consultamos previamente um livro $C$, "e assim até o infinito". ${ }^{15}$

Segundo Ricardo Piglia, o primeiro a ler o leitor, a tirar essa figura da invisibilidade ao conferir a ele um nome próprio, foi o também escritor argentino Macedonio Fernández. ${ }^{16}$ Museo de la novela de la eterna, um trabalho de

${ }^{12}$ ANTELO, Raúl. Destruição e anacronismo. In: Tempos de Babel. São Paulo: Lumme Editor, 2007.

13 Ibidem, p. 10.

${ }^{14}$ BARTHES, Roland. Da leitura. In: O rumor da língua. Trad. Mario Laranjeira. São Paulo: Martins Fontes, 2004.

${ }^{15}$ BORGES, Jorge Luis. A biblioteca de Babel. In: Ficções. Trad. Davi Arrigucci Jr. São Paulo: Companhia das Letras, 2007, p. 76.

16 PIGLIA, Ricardo. O último leitor. Trad. Heloisa Jahn. São Paulo: Companhia das Letras, 2006. 
quase quatro décadas, reúne prólogos todos redigidos para apresentar um romance que nunca se materializa - pertence a um futuro que não cessa de vir. ${ }^{17}$ Constrói, nesta galeria de inícios, a leitura não do romance, mas do leitor. O exercício de Macedonio implica em uma espécie de taxonomia daquele que lê, organizando-o em tipos: "lector artista", "lector de desenlace", "lector personaje", "lector seguido" e o seu contraponto, "lector salteado". Essas personagens são imaginadas não somente por aquele que escreve nem tampouco somente por aquele que lê, mas emergem do contato entre ambos. ${ }^{18}$ Museo é justamente dedicado ao "lector salteado". Sobre este, escreve Macedonio:

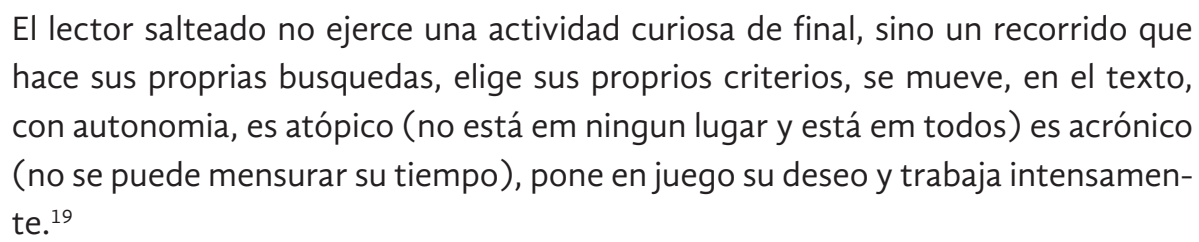

Macedonio considera um sábio esse leitor que lê mal, pula páginas, não concebe o livro como uma ordenação canônica, e, por isso, está constantemente lendo fora de lugar; o leitor que é capaz não apenas de ler, mas de entre-ler, por dentro, perseguir o texto que está para além do visível. Vale recuperar aqui mais uma vez aquele considerado por Piglia o último leitor por excelência, aquele que "passou a vida lendo, aquele que queimou os olhos na luz da lâmpada". ${ }^{20}$ O leitor Borges, inventor do leitor Pierre Ménard, autor do quixote. ${ }^{21}$ Neste conto, o narrador, após listar a obra visível de Ménard, a conhecida, a publicada, passa a elencar sua outra obra: "a subterrânea, a interminavelmente heroica, a sem-par. Também - pobres possibilidades humanas! - a inconclusa!"22

Borges tem em Macedonio uma espécie de Zaddik, um mestre da mística judaica "cuja doutrina da lei é menos importante do que o fato de ele próprio ser a lei". ${ }^{23}$ Aos olhos do discípulo Borges, que espiava à espreita, seu mestre

\footnotetext{
${ }^{17}$ FERNÁNDEZ, Macedonio. Museo de la novela de la eterna. Ana Maria Camblong e Adolfo de Obieta (Org.). Buenos Aires, Rio de Janeiro: Alca XX/UFRJ, 1996.

${ }^{18}$ BARBOSA, Davi Pessoa Carneiro. A escritura ambivalente: Elsa Morante-Macedonio Fernández. Tese (Doutorado em Teoria Literária) - Programa de Pós-Graduação em Literatura, Universidade Federal de Santa Catarina, Florianópolis, 2013.

19 FERNÁNDEZ, Macedonio. Museo de la novela de la eterna, op. cit., p. 119.

${ }^{20}$ PIGLIA, Ricardo. $O$ último leitor, op. cit., p. 19.

${ }^{21}$ BORGES, Jorge Luis. Pierre Ménard, autor do Quixote. In: Ficções. op. cit.

22 Ibidem, p. 37.

${ }^{23}$ ANTELO, Raul. Desleituras criativas. In: Transgressão e Modernidade. Ponta Grossa: EdUEPG, 2001, p. 157.
} 
alcançara o cerne da "transcrição fiel da realidade", a poesia. Para Antelo, que coloca em contato o par Macedonio/Borges e Ismael Nery/Murilo Mendes, tal transcrição fiel da realidade é a "combinação complementária de estratégias de expropriação e apropriação". ${ }^{24}$ Por apropriação entende-se um "camuflar a autoria em leitura de outros textos" 25 e por expropriação, fazer com que a cópia de um texto, que em quase nada o altera, seja uma forma de leitura. Essa segunda proposição é a obra subterrânea, vestigial de Ménard: o Quixote. Não outro Quixote, ou a cópia do Quixote de Cervantes, mas um Quixote cujas páginas "coincidissem - palavra por palavra e linha por linha - com as de Miguel de Cervantes". ${ }^{26}$

Seguindo a trilha de Macedonio, o narrador do conto de Borges considera lícito ver traços do Quixote de Ménard no Quixote final. Como se o Quixote de Cervantes guardasse a possibilidade de ser traduzido pelo autor-copista (a traduzibilidade sobre a qual fala Walter Benjamin). ${ }^{27}$ É isso que torna possível que se considere a obra inacabada de Ménard como a escrita prévia de Cervantes, e não o inverso. É o primeiro inventor, sustenta Macedonio, quem sempre executa o plágio, não o segundo.

Essa caça arqueológica está também em Michel Foucault leitor do desenho de René Magritte. No cachimbo que "n'est pas une pipe", Foucault vê fragmentos de um caligrama desamarrado; um caligrama duplamente pervertido. Para além da perversão que é própria do caligrama (pois este frustra o afastamento entre o texto e a figura), há uma segunda, alusiva ao derramamento da frase que preenchia a figura ("ceci n'est pas une pipe") para o seu lugar previsível: o de legenda. Porém esse retorno é somente aparência, posto que “[...] as palavras que posso ler agora sob o desenho são, elas próprias, palavras desenhadas - imagens de palavras que o pintor colocou fora do cachimbo, mas no perímetro geral (aliás, indeterminável) de seu desenho." ${ }^{28}$

Ler os traços de um Quixote no outro, ver o caligrama no cachimbo de Magritte é realizar a desleitura que nos propõe Raúl Antelo: enxergar o andaime na arquitetura final. Apesar de movimentos marcados por etimologias diferentes, o des-ler de Antelo e o entre-ler do leitor salteado podem se dar concomitantemente - ainda que esse "ao mesmo tempo" seja próprio de um

${ }^{24}$ Ibidem, p. 158.

25 Ibidem, p. 158.

26 BORGES, Jorge Luis. Pierre Ménard, autor do Quixote. In: Ficções, op. cit., p. 38.

27 BENJAMIN, Walter. A tarefa do tradutor. In: Escritos sobre mito e linguagem. Trad. Susana Kampff Lages e Ernani Chaves. São Paulo: Editora 34, 2011.

${ }^{28}$ FOUCAULT, Michel. Isto não é um cachimbo. Trad. Jorge Coli. Rio de Janeiro: Paz e Terra, 2008, p. 24. 
tempo anacrônico. O leitor pode ler um texto por dentro como se raspasse um palimpsesto e fizesse emergir vestígios sobrepostos por camadas; é capaz de atravessar um texto aos saltos por entre suas páginas.

Volto a Faulkner. Poderia, forçosamente, alegar que o escritor norteamericano, ao intercalar capítulos de novelas diferentes, deseja uma leitura não conformada à linearidade. Ao leitor que o enfrenta não haveria, portanto, outra saída que não a de saltar de uma história à outra, e elaborar, assim, uma leitura salteada. Mas o leitor salteado não seria aquele que frustra as intenções do escritor e produz seu próprio sentido no contato com o texto ao pular por entre suas linhas e páginas? Se o propósito de Faulkner com essa mescla de narrativas é instar quem lê a saltar ordenadamente, talvez o leitor salteado seja justamente aquele que recusa tal comando e propõe um outro modo. Glauber, na carta a Saraceni, refere-se ao livro como Palmeiras bravas em vez de Palmeiras selvagens, o que sugere que sua leitura se deu a partir da edição portuguesa do livro, não da brasileira. Uma parte das edições portuguesas concebeu as duas narrativas em livros separados (Palmeiras bravas e Rio velho) o que leva a intuir que a leitura do cineasta não obedeceu a essa interpolação. ${ }^{29}$

Salteador, Glauber lia e escrevia obsessivamente. Ivana Bentes, responsável pela reunião de suas cartas em livro, afirma que o cineasta passou mais tempo dos 42 anos que viveu curvado sobre sua máquina de escrever do que com uma câmera na mão. Sublinho uma carta escrita por ele aos 13 anos. Nela, o jovem Glauber compõe para seu tio Wilson Mendes de Andrade uma espécie de inventário de suas leituras mais recentes. Edgar Allan Poe e Rudyard Kipling ( 'E aquela sua poesia 'Se' é o que de mais belo pode haver em matéria de filosofia, mas que considero por assim dizer impraticável"30); Charles Dickens, Robert Stevenson; Jorge Amado, Érico Veríssimo; Schopenhauer, Nietzsche, e comentários acerca da filosofia de Bacon, Platão, Aristóteles, Sócrates, Spinoza, Voltaire. ("Filosofia faz-nos pensar melhor acerca do mundo e dos homens"31).

Como insinua esta carta, os interesses que o chamavam à leitura eram tão dispersos e apaixonados quanto os rompantes de sua escritura. Atravessava "política, filosofia, psicanálise, cinema, estruturalismo, semiologia e literatu-

\footnotetext{
${ }^{29}$ Somo a essa intuição o fato de Glauber não mencionar, nas cartas, nenhuma passagem de $O$ velho ao referir-se a Palmeiras selvagens.

${ }^{30}$ ROCHA, Glauber. Cartas ao mundo, op. cit., p. 79.

${ }^{31}$ Ibidem, p. 79-80.
} 
ra". ${ }^{32}$ Dizia preferir a leitura ao carnaval. ${ }^{33} \mathrm{Em}$ outro momento, dizia preferir a leitura às mulheres. ${ }^{34}$

Em carta destinada a Walter da Silveira, datada de 1962, escreveu: "Eu tenho defeitos culturais do jovem brasileiro, malformado nas universidades e mal informado através de leituras confusas e conversas idem". ${ }^{35}$ A confusão de sua leitura e de sua formação - Glauber abandonou a Universidade e o Direito para se formar Cineasta ${ }^{36}$ - é confirmada por Cacá Diegues em depoimento colhido por Bentes. Glauber lia constantemente, mas era um leitor errático, "diagonal, que sintetizava uma formação fragmentada, com lacunas, 'incultura' no sentido enciclopédico e acadêmico". ${ }^{37}$ Começava um livro para logo perseguir outro, que o levava a outro e a outro, no infinito método regressivo borgeano. Ao finalizar um livro que o interessava, não o dava por acabado. 0 já citado Angústia, de Graciliano Ramos, leu por três vezes. ${ }^{38}$ Menina morta, de Cornélio Penna, duas. ${ }^{39}$

Recupero a carta de Glauber para Saraceni. Mais adiante, ele exclama ao amigo: "Precisamos trabalhar juntos, como Godard e Truffaut." ${ }^{40}$ Essa pista deixada por Glauber nos faz rastrear a trilha de um segundo leitor de Faulkner.

Em uma cena de À bout de souffle (Acossado), filme que Jean-Luc Godard realiza em 1959 junto a Truffaut, a americana Patricia Franchini fuma um cigarro ao lado do namorado Michael Poiccard. Plano médio, Patricia tem os olhos maquiados, usa um vestido listrado, enquanto Michael está despido da cintura para cima e cobre as pernas com um lençol branco. Patricia segura nas mãos um livro e pergunta:

32 Ibidem, p. 57.

${ }^{33}$ Em carta enviada de São Paulo, em 01 de fevereiro de 1959, aos pais, Lucia e Adamastor Rocha, escreve Glauber: "Vou passar o Carnaval em Campinas, na casa do Nonô e Evandro. Lá eu vou ficar lendo, por que não gosto de folia. Depois vou até o Rio acabar os filmes". Ibidem, p.106.

${ }^{34}$ Em carta enviada de Salvador, entre dezembro e 1962 e março e 1963, a Paulo César Saraceni, escreve Glauber: "Agora eu quero fazer ginástica, ler e escrever. Aqui não tem mulher, pouco me interessa". Ibidem, p. 178.

35 Ibidem, p. 171, grifo meu.

${ }^{36}$ Segundo Sylvie Pierre, biógrafa e amiga de Glauber, os três anos de Glauber na universidade serviram, entre outros aspectos, para ele "torcer o nariz/captar/digerir/rejeitar/tomar emprestado/imitar apenas o suficiente os eflúvios da cultura acadêmica, vacinando-se para sempre contra ela, situar-se de través, acima, abaixo, de lado, e tornar-se, no entanto, sociologicamente, intelectualizado". PIERRE, Sylvie. Glauber Rocha - textos e entrevistas com Glauber Rocha. Trad. Eleonora Bottmann. Campinas: Papirus Editora, 1996, p. 49.

37 ROCHA, Glauber. Cartas ao mundo, op. cit., p. 57.

38 "Sei porque li o livro três vezes." Ibidem, p. 192.

39 "Li duas vezes e detalhadamente, Menina morta." Ibidem, p. 193.

40 Ibidem, p. 194. 
PATRICIA: Conhece William Faulkner?

MICHAEL: Não. Quem é? Dormiu com ele?

PATRICIA: Não, meu querido.

MICHAEL: Então não quero saber.

PATRICIA: É um escritor, do qual eu gosto. Leu Palmeiras selvagens?

MICHAEL: Já disse que não. Tira a roupa.

PATRICIA: Escuta. A última frase é muito bonita: "Between grief and nothing I will take grief". "Entre o sofrimento e o nada, escolho o sofrimento". (Para Michael) O que você escolheria? ${ }^{41}$

Godard cultivou e aperfeiçoou, ao longo dos anos, seu forte gosto pela citação. Há, na superfície e no subterrâneo de seus filmes, o sobrevoo realizado em uma biblioteca infinita por este cineasta que sempre se sonhou romancista. Godard passa boa parte do seu tempo folheando livros em uma verdadeira operação de caça (para ficarmos em Michel de Certeau ${ }^{42}$ ) por fragmentos que o interessem e que poderão ter alguma serventia. Ama a literatura, mas dessacraliza seus objetos: quando gosta de uma passagem, não hesita em arrancar a página do exemplar em questão. Guarda para mais tarde, coleciona citações, retém um vasto dossiê fragmentado. Alguns livros, lê em fast forward, não parte do início, nem chega a seu fim. Salta, ao gosto de Macedonio, por entre suas páginas, pois sustenta que, se há uma passagem importante no livro, ela emergirá aos seus olhos neste folhear. Outros livros e textos, entretanto, percorre com atenção microscópica. Sobre o conceito de história, de Walter Benjamin, leu durante um ano. A morte de Virgílio, de Hermann Broch, durante dez. ${ }^{43}$ Antes de iniciar qualquer trabalho - seja o de cineasta ou de crítico - sempre recorreu ao seu estoque de frases soltas. Tal qual um Ménard, expropria (copia as frases sem alterá-las) e, tal qual um Macedonio, apropria (pois nem sempre sabe dizer a origem ${ }^{44}$ daquilo que cita).

${ }^{41}$ GODARD, Jean-Luc. À Bout de soufflé. Produção: Georges de Beauregard. Paris: Studiocanal - Société Nouvelle de Cinématographie, 1959, 1 Blu-ray.

${ }^{42}$ CERTEAU, Michel. A invenção do cotidiano. Trad. Ephraim Ferreira Alves. Petrópolis, Rio de Janeiro: Editora Vozes, 1998. Michel de Certeau, em suas reflexões sobre a leitura como uma operação de caça, recupera Guy Rosolato, quem afirma o ato de ler como uma impertinente ausência. Ao mesmo tempo, o psicanalista se questiona se seria a leitura um exercício de ubiquidade. Ler como um estar em todos os lugares, e também como um não estar onde se está. Uma ausência na presença.

${ }^{43}$ COUTINHO, Mario Alves. O prazer material de escrever - entrevista com Alain Bergala. Devires, v.4, n.1, p. 84-101, sem. 2007. Essa figuração de um Godard leitor foi realizada por Alain Bergala, crítico francês próximo a Godard e quem editou os textos do cineasta escritos para Cahiers du Cinéma e para outras publicações. Essa reunião foi publicada em dois tomos intitulados Jean-Luc Godard par Jean-Luc Godard. Bergala, quem acompanhou os passos de Godard desde Pierrot le fou, falou sobre a relação dele com a literatura em entrevista concedida ao pesquisador Mario Alves Coutinho, doutor em Literatura Comparada pela UFMG.

44 "Ao preparar um filme, Godard costuma fazer um pequeno caderno no qual ele cola as frases, sem se preocupar com o nome do autor. Às vezes, há dez frases numa mesma página do caderno, e nem sempre Godard sabe dizer a origem delas. Para ele, uma vez destacada do livro, a frase passa a ser um material". Ibidem, p. 90. 
A citação em Godard atinge máxima potência em Histoire(s) du cinema. Por dez anos, o cineasta francês engendrou um intenso exercício de montagem não apenas para reverenciar a tradição que educou seu olhar, mas também para tocar um real perdido (ou o momento que frustra a formalização, como formula Antelo) no contemporâneo. ${ }^{45}$ Em quatro horas e meia, Godard colide imagens, sons e textos passados com o presente, conferindo a esses passados uma legibilidade somente possível nesse reencontro, nessa remontagem. ${ }^{46}$ Antelo, ao ler Histoire(s) du cinema através de Didi-Huberman, aproxima o recorte e a colagem godardianos ao atlas Mnemosyne de Aby Warburg e ao Livro das passagens, de Benjamin. ${ }^{47}$

Estes artistas são contemporâneos no sentido proposto por Agamben, ${ }^{48}$ são rapsódicos ${ }^{49}$ no olhar de Antelo. Detêm uma escritura não limitada ao tempo e ao espaço que Ihes são próprios, mas relacionada ao resgate de tradições pertencentes a uma anterioridade e a uma distância. Tal escritura é a da tradução, que não serve à sacralização dos textos passados, mas sim, dispõese a profaná-los. ${ }^{50}$ A história do cinema construída por Godard profana uma historiografia do cinema.

45 AGAMBEN, Giorgio. O que é contemporâneo? In: O que é o contemporâneo? e outros ensaios. Trad. Vinicius Nicastro Honesko. Chapecó: Argos, 2009, p. 55-77. Ser contemporâneo, conforme escreveu o filósofo italiano em seminário proferido entre 2006 e 2007, abriga, simultaneamente, o princípio de aderência e de distância do seu "próprio" tempo. Pertence ao "próprio tempo" - ou a esse presente inapreensível, que é tal qual um passo dado em suspenso em direção não a um futuro cronológico, mas a um tempo que não cessa de vir - aquele que não se coaduna exatamente às pretensões e exigências impostas por esse tempo e consegue guardar dele uma distância. Esta distância, entretanto, não é o afastamento do nostálgico, que preferiria viver em qualquer outro tempo que não o seu. É contemporâneo aquele que se reconhece enquanto próprio de seu tempo, mas, justamente por conseguir nele produzir um deslocamento, um anacronismo, torna-se "capaz, mais do que os outros, de perceber e apreender o seu tempo" Ibidem, p. 58. Transgride, pois, o tempo domesticado, dado pela cronologia histórica.

${ }^{46}$ ANTELO, Raúl. Ler para frustrar a formalização. In: OLINTO, Heidrun Krieger; Karl Erik Schøllhammer; Mariana Simoni. (Org.). Literatura e artes na crítica contemporânea. Rio de Janeiro: Editora PUC-Rio, 2016, p. 283-297.

${ }^{47}$ Mobile, de Michel Butor também poderia compor essa constelação. Trata-se de uma série de frases, trechos de notícias, palavras sobre a América apresentadas em ordem alfabética, a mais pueril das ordens. Segundo Roland Barthes, Butor feriu a ideia de livro ao abraçar a possibilidade de vazio e ao eliminar o princípio tradicional de desenvolvimento. "O contínuo de Mobile repete, mas combina diferentemente o que repete. Disso decorre que o primeiro (o contínuo retórico) nunca volta ao que expôs, enquanto o segundo (o contínuo de Mobile) volta, lembra: o novo está sempre acompanhado do antigo; é, se quiser, um contínuo fugado, no qual os fragmentos identificáveis entram sempre de novo na corrida". BARTHES, Roland. Literatura e descontínuo. In: Crítica e verdade. Trad. Leyla Perrone-Moysés. São Paulo: Perspectiva, 2017, p. 122 .

48 Sugiro uma releitura da nota 44.

49 ANTELO, Raúl. Ler para frustrar a formalização, op. cit., p. 5.

50 , Idem, A tradução infinita. Revista Letras, n. 95, p. 182-202, 2017 
Retornemos à biblioteca infinita de Godard. Há nela um exemplar (ou uma página rasgada) de O fazedor, livro publicado por Borges em 1960. ${ }^{51}$ Seu fragmento favorito é o epílogo. ${ }^{52}$ Nele, um homem se dá a tarefa de construir um mundo. Cria, por anos, imagens de províncias, reinos, baías, peixes, moradas, cavalos, pessoas. Pouco antes de morrer descobre que esse "paciente labirinto de linhas traça a imagem de seu rosto." ${ }^{53}$

Vinte anos antes de perceber a imagem de seu rosto neste labirinto de referências, Borges debruçava-se sobre Wild palms, de Faulkner, para traduzi- lo em Las palmeras selvajes. Há três artigos sobre Faulkner escritos por Borges reunidos no semanário $E l$ hogar. ${ }^{54} \mathrm{O}$ terceiro deles, o menos entusiasmado de todos, é sobre Palmeiras selvagens. Para o argentino, a técnica faulkeriana de expressar a história através da intensidade de seus personagens, bem-sucedida em Absalom, Absalom! e The unvanquished, perde sua potência em Wild palms. "São menos atraentes que entediantes, menos justificáveis que estimulantes." 55

Apesar da aparente pouca estima em relação a este livro, a tradução de Borges foi responsável por introduzir Faulkner na América Latina. Em mais de um momento, Borges pensou a tarefa do tradutor. Em um texto menos conhecido seu sobre o tema, de 1926, recuperado por Antelo, o argentino reconhece duas classificações possíveis para a tradução: a da literalidade e a da perífrase. ${ }^{56} \mathrm{~A}$ primeira, romântica, reivindica o autor, jamais a obra; enquanto a segunda, clássica, interessa-se pela obra, nunca pelo artista. Declara, então, sua preferência pela perífrase clássica, que, em muito se assemelha ao ato de profanar sobre o qual fala Agamben. Traduzir não se trata de ser fiel ao literal, mas sim dedicar toda a lealdade a uma certa estranheza daquilo que se traduz. Nem que, para isso, seja necessário extrapolar o "original”, enfatizá-lo a ponto de torná-lo mentiroso. O tradutor é um falsário. E Borges também não o seria?

Paira uma dúvida se Borges de fato traduziu Wild palms sozinho. ${ }^{57}$ Ao menos duas evidências sustentam que sim. Em seu ensaio autobiográfico, aponta que, entre 1937 e 1946, traduziu Virginia Woolf e Faulkner, enquanto trabaIhava como bibliotecário municipal. Além disso, em Borges on writing, reu-

\footnotetext{
${ }^{51}$ BORGES, Jorge Luis. O fazedor. Trad. Josely Vianna Baptista. São Paulo: Globo, 2000.

52 ROUD, Richard. Introduction. In: Godard on Godard. Nova York: Da Capo Press, 1986, p. 7-10.

53 BORGES, Jorge Luis. O fazedor. In: Ficções, op. cit., p. 73.

${ }^{54}$ DAY, Douglas. Borges, Faulkner and the Wild Palms. The Virginia Quartely Review p. 109-118, 1980.

55 Ibidem, p. 112.

${ }^{56}$ ANTELO, Raúl. A tradução infinita. Revista Letras, op. cit.

57 DAY, Douglas. Borges, Faulkner and the Wild Palms. The Virginia Quartely Review, op. cit.
} 
nião de seminários proferidos pelo argentino, ele recorda ter sido criticado por sua tradução de Wild palms. Porém, uma outra evidência sugere que sua mãe ou colaborou com o filho na empreitada ou a realizou completamente. No já mencionado ensaio autobiográfico, Borges afirma que Leonor Acevedo Borges foi quem realizou as traduções de Melville, Woolf e Faulkner normalmente atribuídas a ele.

Glauber, Godard e Borges leem Faulkner, mas também leem uns aos outros, e leem a si mesmos. A leitura que engendram não é própria de uma forma, mas de uma força e, por isso, é sempre relacional, sempre plural. ${ }^{58}$ No caso deles, uma leitura ora falsa, ora incompleta, ora inconclusa. Talvez o caso exemplar dessa incompletude esteja na leitura de Glauber Rocha. Desde seu primeiro contato com Palmeiras selvagens, sonhou em adaptá-lo para o cinema. Esse sonho o assombrou quase até o fim da vida. Escreve, do Rio de Janeiro, em 1978, ao produtor Dan Talbot, em francês: "Quero também ficar nos Estados Unidos para tentar enfim realizar meu antigo sonho, que é filmar THE WILD PALMS de Faulkner...Espero que um outro não faça isso antes de mim." 59

Talvez seja Palmeiras selvagens sua obra subterrânea, interminavelmente heroica, sem-par, inconclusa. Mas, nos ensina Piglia, o que podemos imaginar sempre existe, em outra escala, em outro tempo, como num sonho. ${ }^{60} \mathrm{E}$ há nos sonhos um modo de ler. Borges bem o sabe. Em Buenos Aires, em 15 de março de 1975, ele está na companhia de Ernesto Sabato e Orlando Barone na rua Maipú, no antigo apartamento da pintora uruguaia Renné Noetinger. No edifício ao lado, sua mãe, Leonor, quase aos cem anos, morreria muito em breve. Ele, então, se recorda de um sonho que teve fazia algumas noites:

Eu tinha encontrado um livro inglês do século XVII e me dizia que era muito lindo ter achado essa edição, mas depois pensei que se eu estava sonhando, no outro dia não ia encontrá-lo. Então eu me disse: vou colocar o livro em um lugar seguro, e o coloquei em uma gaveta da biblioteca. Assim eu ia poder encontrá-lo quando acordasse. ${ }^{61}$

\footnotetext{
${ }^{58}$ ANTELO, Raúl. A aporia da leitura. Ipotesi, revista de estudos literários, v.7, n.1, p. 31-45, 2002.

${ }^{59}$ ROCHA, Glauber. Cartas ao mundo, op. cit., p. 537.

60 PIGLIA, Ricardo. O último leitor, op. cit.

${ }^{61}$ BARONE, Orlando. Borges e Sabato: diálogos. Trad. Maria Paula Gurgel Ribeiro. São Paulo: Globo, 2005, p. 165.
} 